\title{
Synthesis of Coaxial Nanotubes of $\mathrm{MoS}_{2}$ and Carbon
}

\author{
P.Santiago ${ }^{1,2}$, C. Reza-San Germán ${ }^{2}$, M. Pérez-Alvarez ${ }^{2}$, L. Rendón ${ }^{1}$ and J. Ascencio ${ }^{3}$ \\ ${ }^{1}$ Instituto de Física UNAM A.P. 20-364, C.P. 01000, Mexico D.F., Mexico \\ ${ }^{2}$ Instituto Nacional de Investigaciones Nucleares K.m. 36.5, Salazar Edo. De Mexico \\ ${ }^{3}$ Instituto Mexicano del Petróleo
}

In the recent years the discovery of carbon nanotubes by Ijima (1) has triggered a very important field of research in materials science. Indeed the many interesting properties of carbon nanotubes make them especially promising materials for different applications. In the same way, transition metal chalcogenides such as $\mathrm{WS}_{2}$ and $\mathrm{MoS}_{2}$ are able to generate tubular structures as a consequence of their two-dimensional molecular nature and their properties as useful catalytic materials remain under study. In the present work, we try to explore both tubular abilities to generate coaxial nanotubes in order to understand these new exotic structures.

The $\mathrm{MoS}_{2}$ nanotubes were prepared using a nanoporous alumina template obtained by anodization of aluminum (2). A solution of $\left(\mathrm{NH}_{4}\right)_{2} \mathrm{MoS}_{2}$ in dimethylformamide (DMF) was used as solutionphase precursor. The alumina template was immersed into the solution for few seconds and then died at $70^{\circ} \mathrm{C}$ on a hot plate in order to evaporate the solvent. The sample was loaded into a furnace and submitted to a heat treatment in a mixture of $10 \% \mathrm{H}_{2} / \mathrm{N}_{2}$ at $450^{\circ} \mathrm{C}$. Once the $\mathrm{MoS}_{2}$ nanotubes were produced in the nanoporous alumina template, the sample was submitted to a new heat treatment in a mixture of propylene- $\mathrm{N}_{2}$ at $800^{\circ} \mathrm{C}$. The $\mathrm{MoS}_{2}-\mathrm{C}$ nanotubes were removed from the alumina template using a $\mathrm{NaOH}$ solution and characterized by HRTEM.

Tubular structures were found and they are showed in figure 1. The morphology of the nanotubes shows a very straight tubular structure with the typical $\mathrm{MoS}_{2}$ contrast at the external walls of the tube. However a closer view shows the layer Carbon contrast in the internal part of the tube. The electron diffraction pattern shows the hollow structure of the typical nanotube but (002) reflection has internal structure that could be related with the chilarity of the tube. The (002) planes at the

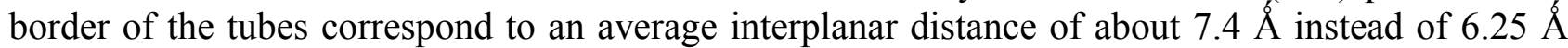
expected for $\mathrm{MoS}_{2}$ nanotubes interplanar distance. Hexagonal Moiré structure is also observed in the internal contrast of the tube.

Figure 2 shows a model of $\mathrm{MoS}_{2}$ nanotube with an internal $\mathrm{C}$ nanotube using CERIUS2 (Molecular Simulations Incorporated). This model reproduces the contrast of the HRTEM image and is in a good agreement with the interplanar distance obtained experimentally for $\mathrm{MoS}_{2}$ layers.

From the experimental and theoretical results we can explain the relaxation of the interplanar distance in the $\mathrm{MoS}_{2}$ lattice due to an intercalation of $\mathrm{C}$ layer between two $\mathrm{MoS}_{2}$ layers, however this remain unclear and we are still working on the characterization of this new kind of tubes.

\section{References}

(1) S. ijima, Nature 354, 56 (1991)

(2) C. Zelenski and P. Dorhout. J. Am. Chem. Soc., 120, 734 (1998). 


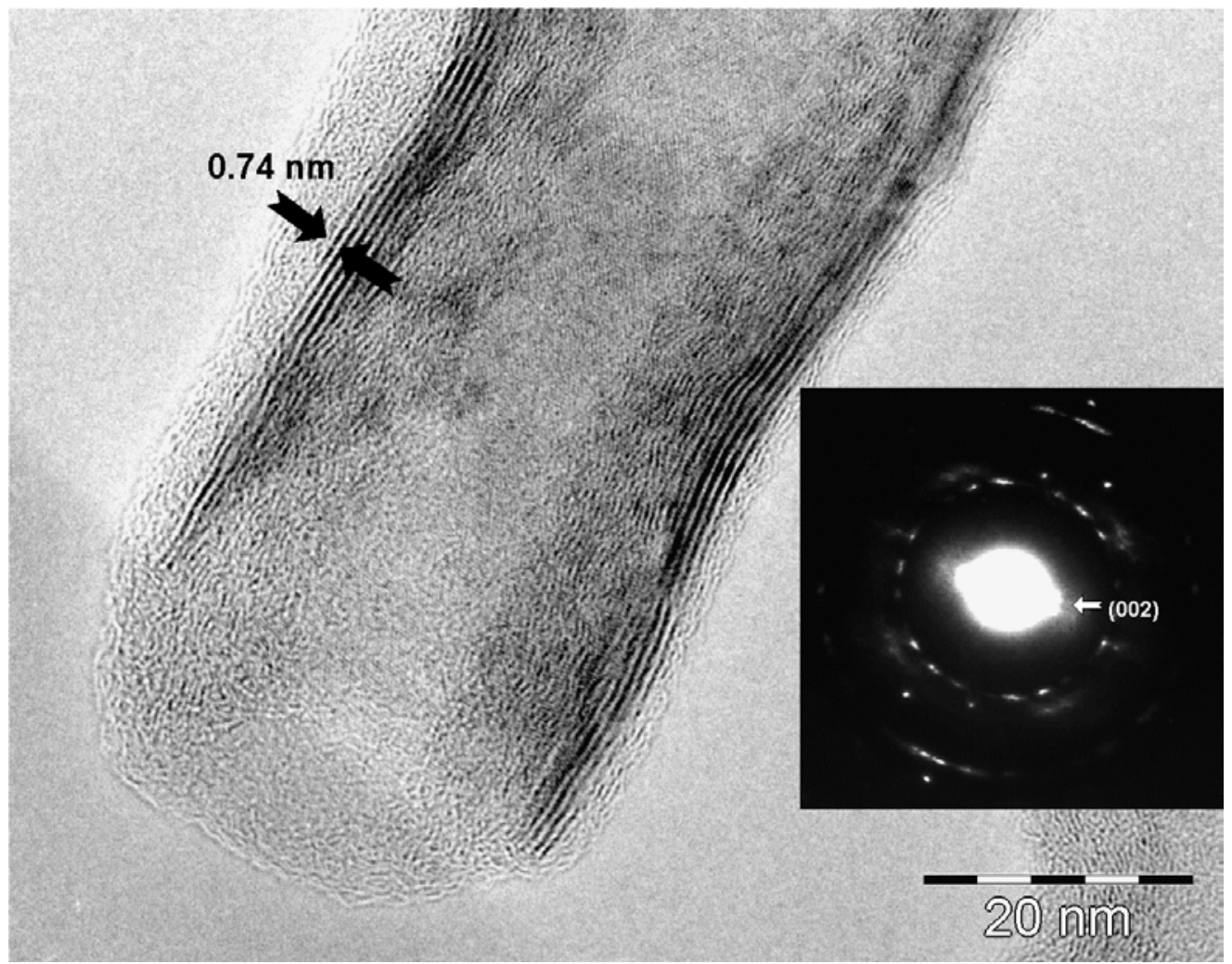

Fig. 1 High resolution image of a coaxial $\mathrm{MoS}_{2}-\mathrm{C}$ nanotube.
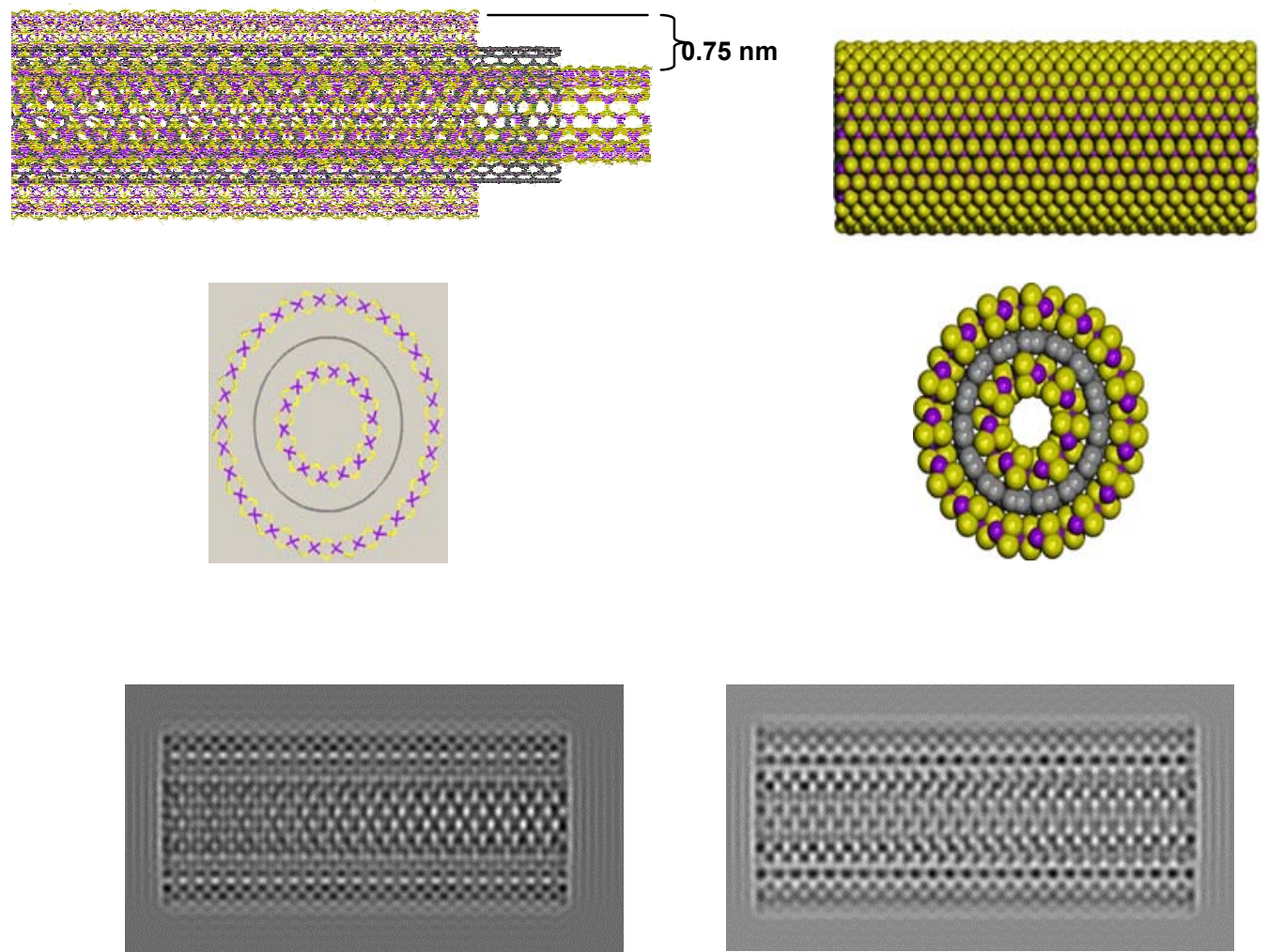

Fig. 2. Theoretical simulation of coaxial nanotubes of $\mathrm{MoS}_{2}$ and Carbon using multislice method. 